\title{
Sustainable development in urban planning
}

\author{
B. M. Al-Hadad \\ Erbil Polytechnic University, Erbil, Iraq
}

\begin{abstract}
The ability of a community for reproduction has a great link with the environments they live in. A plan for an urban area must achieve the objectives and the needs of the people in the area under study. These achievements are strongly linked with economic, environmental, and social factors, as key elements for a sustainable development. A sustainable plan enhances social and environmental relationship with less capital loss. This study has focused on the impacts of transportation and land use planning in urban planning. Transportation and land use planning are the two main pillars of any urban plan that could map the route of how a development in an area would take place in the future. The study has therefore tried to highlight the critical factors for a sustainable development in urban planning, which could guarantee a healthy growth so that the possibility of future degradation is avoided.

Keywords: urban planning, land use planning, sustainable development.
\end{abstract}

\section{Introduction}

The disorder of the industrial city in mid-19th century has led to a movement for urban reform which is now considered as the modern origins of urban planning. A plan for an urban center can include urban renewal, by adapting urban planning methods to existing cities suffering from decline. Later on, the term sustainable development has come to represent an ideal outcome in the sum of all planning objectives. This has taken place in the late 20th century (Wikipedia [1]).

This study tries to highlight the principles behind a sustainable plan for an urban area through the available studies, theories, records of the existing developments/settlements. The outcome of the study could then be briefed into several bullet conclusions in such a way that most of the major principles are handy for consideration whenever they are required for application. The 
following sections try to explain the major issues for a sustainable urban planning especially those are linked with transportation and land use cases.

\section{Approaches for sustainable urban planning}

\subsection{What is urban planning?}

Urban planning is a technical and political process concerned with the use of land and design of the urban environment, including transportation networks, to guide and ensure the orderly development of settlements and communities.
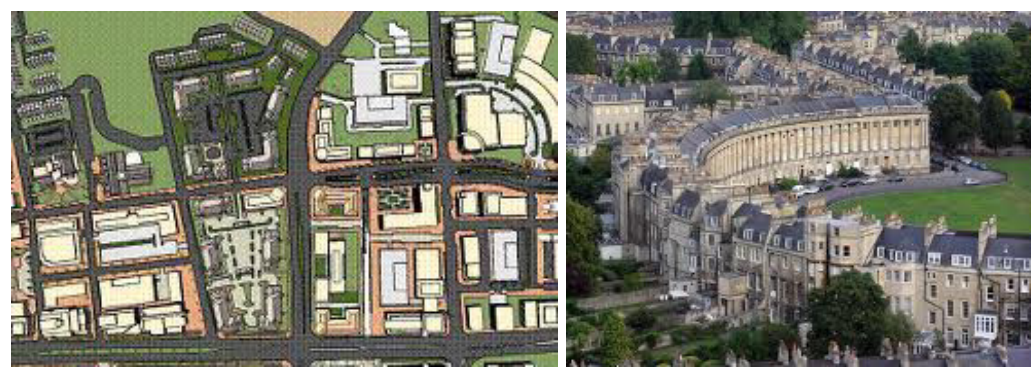

Figure 1: $\quad$ Examples of city developments (Wikipedia [2]).

It is also worth mentioning that urban planning is part of a wider planning theme known as regional planning. Positioning of land use activities, infrastructure, and settlement growth across a larger area of land than an individual urban center (city) is what Regional Planning about (Wikipedia [2]).

\subsection{Sustainability}

Sustainability is the potential for long-term maintenance of well-being with due consideration to ecological, economic, political and cultural aspects.

Sustainable development, as a concept, has been defined in different ways. (Kersten et al. [3]) draws attention to the need of developing methods that emphasize the potential complementarities between economic development and environmental improvement.

In the Brundtland report (Brundtland [4]), sustainable development is defined as "a development that meets the needs of the present without compromising the ability of future generations to meet their own needs."

Sustainable development (Kersten et al. [3]) seeks to produce an approach to compromise among economical, ecological, and social elements and bring them into balance with each other (Figure 2).

\subsection{Sustainable development or loss of cultural urban identity?}

Pusic [5] states that the heritages should be preserved and that sustainable urban development should respect cultural pluralism instead of being used as a pretext to homogenize cities according to the criteria of junk civilization. 


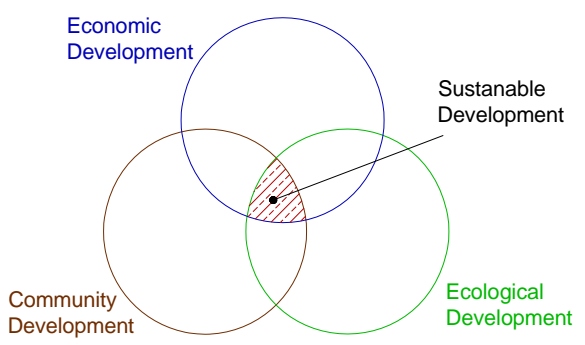

Figure 2: The three interrelated aspects of sustainable development (Kersten et al. [3]).

\section{Sustainability in terms of land use and transportation planning}

\subsection{Land use vs. road networks for a sustainable urban development}

Murray [6] states that the transportation system, especially when it is put close to an urban center, is considered as one of the main elements affecting the environment in terms of congestion and air pollution.

In terms of land use planning, Jha and Kim [7] stated that a new highway/road attracts new housing developments, business, and industry due to improved access, which lead to changes in land use pattern. The new strategy in transportation planning, as mentioned by Jha et al., advocates noise-compatible land-use planning in such a way "that noise-sensitive land uses are either prohibited from being located adjacent to a highway, or that the developments are planned, designed, and constructed in such a way that noise impacts are minimized”. In nearly the same manner, Jaarsma [8] suggests that road network must be dealt with as a major form of land use.

Developing a highway alignment, as stated by Yang et al. [9], must also consider the safety of the users. This can be achieved by adhering to the geometric design policies of the relevant national and/or international design standards of the road type. This allows for the efficient movement of people and goods (Department for Transport [10]).

\subsection{Land uses vs. accessibility for a sustainable urban development}

The presence of different settlements and different land uses in an area may enhance socio-economic activities and activates more traffic generation. Thus, providing access to these settlements will enhance the socio-economic activities of the area (Bruton [11]). Kitamura and Fujii [12] stated that a good plan for a transportation project should also satisfy accessibility.

Figure 3 below illustrates that how access can be improved by providing compromised location for the highway development. In such a case the proximity and accessibility should be balanced (Al-Hadad [13]). 


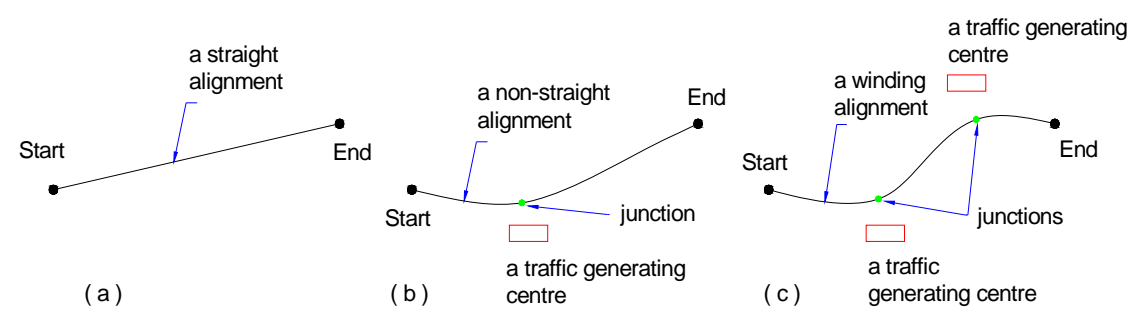

Figure 3: A typical illustration for the effect of access provision on highway alignment (Al-Hadad [13]).

\subsection{Public participation, decision making, and transportation planning}

Applying a system for decision making that incorporate public participation enhances for a project proposal to take place. Meyer and Miller [14] believed that the planning process must provide opportunities for participation to all interested groups to facilitate satisfaction of the decision-making process.

On the other hand, Tang and Waters [15] stated that public participation at an early planning stage allows the planner to consider the requirements at the beginning of the project.

\section{Smart growth}

Since the 1990s, the activist/environmentalist approach to planning has grown into the Smart Growth movement, characterized by the focus on more sustainable and less environmentally damaging forms of development.

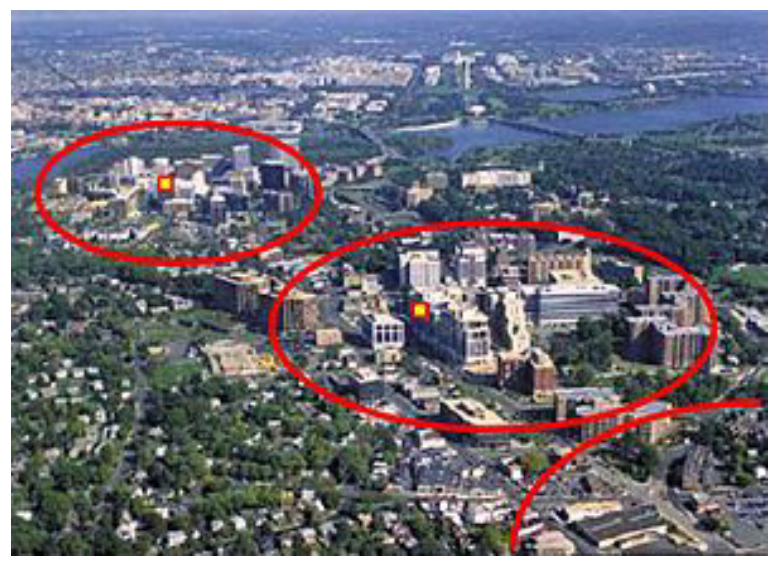

Figure 4: Aerial view of Rosslyn-Ballston corridor in Arlington, Virginia. High density, mixed use development (smart growth) (Wikipedia [16]). 
Smart growth supports the integration of mixed land uses into communities as a critical component of achieving better places to live. Putting uses in close proximity to one another has benefits for transportation alternatives to driving, security, community cohesiveness, local economies, and general quality of life issues. Smart growth strives to provide a mean for communities to alter the planning context that currently renders mixed land uses illegal in most of the country (Wikipedia [16]).

The preparation and implementation of a robust travel plan that promotes use of sustainable transport modes such as walking; cycling and public transport is an effective means of achieving this.

\section{Discussions and recommendations}

Referring to the above facts and principles of a sustainable urban plan and smart growth, planning for an urban area in general, Koya city as a specific case, should take the following views into consideration for a healthy growth so that the development is sustainable and/or smart:

\subsection{Specific considerations}

1. Producing or developing an integrated road network not only in the urban center of Koya city but the plan should also include all the sub-districts and the villages located within the municipality border of Koya region. This matches the regional plan policies of international standards. This provides access for the settlements in the region and enhances social and economic generations. These achievements promote sustainability of the area under consideration.

2. The main road links/highway should be positioned at their optimum locations. An optimum location is a location that reduces journey cost, construction cost, maintenance cost. Optimum road location provides less damage to the natural environment and leads to produce less noise and pollution.

3. Setting a system for traffic movements that includes the different transportation modes.

4. Promote the use of sustainable transport modes such as walking, cycling and public transport. An active system for public transport can reduce the number of passenger cars, reduces $\mathrm{CO} 2$ emissions, reduces congestions, saves money, and consequently a more green and friendly environment. Thus, a sustainable environment is guaranteed.

5. Safety of the road users, especially the vulnerable ones like pedestrians and cyclists, must be as high as possible.

6. Considerations should be given to the land use change whenever a new highway/road development is planned for or taken place.

7. The strategy of noise-compatible land-use planning need to be adopted in such a way that noise-sensitive land uses (like schools, hospitals, etc.) is either prohibited from being located adjacent to a highway, or that the developments are planned, designed, and constructed in such a way that noise impacts are minimized. 
8. Providing standard car parking especially in the CBD (Central business district/ city center) areas. The lack of an efficient car park has paralyzed the transport system of Koya city center zone.

\subsection{General considerations}

1. Generating a system for decision making with the participation of the city's own people on the plan for any proposed development. Public participation may help to define the project proposal more accurately, which could ease making the decision for the development either to take place or not.

2. Koya heritages must be preserved and rehabilitated (e.g. Koya old market "Bazari Qaisari as it is known with its people”, Xani Mahmudaxa, Qishlay koya, Ashi awi hamamok, etc). These heritages define the cultural and historical identity of the city that could be utilized for tourist attractions, thus promoting the income of the city.

\section{Conclusions}

Sustainability in urban planning is important so that the future degradation is avoided. This could also help in reducing the migration of the people in the area to better places to live. It can be concluded that a plan for an urban area should also give consideration to the abutting settlements and land uses at regional level so that the development is more comprehensive and global than being local. This enhances the economic and social activities of the area with less damage to the environment.

\section{References}

[1] Wikipedia (1), (2013). Urban Planning, Available on <http://en.wikipedia.org/wiki/Urban_planning $>$. [Accessed: $11^{\text {th }}$ September 2013]

[2] Wikipedia (2), (2013). Regional Planning, Available on <http://en.wikipedia.org/wiki/Regional_planning>. [Accessed: 11th September 2013]

[3] Kersten, G.E., Mikolajuk, Z. \& Yeh, A.G., (1999). Decision Support System for Sustainable Development, A research Book of Methods and Applications, Kluwer Academic Publishers, Hingham, MA, USA.

[4] Brundtland, G.H., (1987). Our Common Future: Report of the World on Environment and Development, Centre of a World in Balance, Netherlands. Available from <http://www.-Worldinbalance.net /agreements /1987-brundtland.php>. [Accessed: 03 January 2009].

[5] Pusic. L, 1998. Sustainable Development and the Future of Cities, Publisher: Intermediate Technology Publications Limited, pp. 185-194, London, UK.

[6] Murray, T. Alan., (2001). Strategic Analysis of Public Transport Coverage, Socio-Economic Planning Sciences, Vol. 35, pp. 175-188. 
[7] Jha, M.K. \& Kim, E., (2006). Highway optimization based on accessibility, proximity and land use change, Journal of Transportation Engineering, Vol. 132, No. 5, pp. 435-439.

[8] Jaarsma, C.F., (1997). Approaches for the planning of rural road network according to Sustainable land use planning, Landscape and Urban Planning, Vol. 39, pp. 47-54.

[9] Yang, Z., Feng, T. \& Peng, J., (2003). Optimizing Highway Alignment in Road Network, Proceeding of the Eastern Asia Society for Transportation Studies, Vol. 4, pp. 373-380.

[10] Department for Transport, 2013. The Strategic Road Network and the Delivery of Sustainable Development, London, UK.

[11] Bruton, M. J., (1992). Introduction to Transport Planning, UCL press, UK.

[12] Kitamura, R. \& Fujii, S., (1997). Time Use Data, Analysis and Modeling: Toward the Next Generation of Transportation Planning Methodologies, Transport Policy, Vol. 4, No. 4, pp. 225-235.

[13] Al-Hadad, B., (2011). An Approach to the Highway Alignment Development Process Using Genetic Algorithm Based Optimisation, PhD thesis, Nottingham University, UK.

[14] Meyer, M.D. \& Miller, E.J., (2001). Urban Transportation Planning, McGraw-Hill.

[15] Tang, K.X. \& Waters, N.M., (2005). The Internet, GIS and Public Participation in Transportation Planning, Progress in Planning, Vol. 64, Issue 1, pp. 7-62.

[16] Wikipedia (4), (2013). Land Use Planning, Available at <http://en.wikipedia.org/wiki/Land-use_planning\#cite_note-Walters.2C_D. .2C_2007-5>. [Accessed: 10th September 2013] 